\title{
Systemic Analysis of Food Supply and Distribution Systems in City-Region Systems-An Examination of FAO's Policy Guidelines towards Sustainable Agri-Food Systems
}

\author{
Vanessa Armendáriz 1,*, Stefano Armenia ${ }^{1,2, *}$ and Alberto Stanislao Atzori ${ }^{2,3}$ \\ 1 DIAG-Dipartimento di Ingegneria Informatica, Automatica e Gestionale \\ "Antonio Ruberti" - Sapienza University of Rome, Via Ariosto 25, Roma 00185, Italy \\ 2 SYDIC—System Dynamics Italian Chapter (www.systemdynamics.it), Via Carlo Sereni 12, \\ Rome 00146, Italy; asatzori@uniss.it \\ 3 Dipartimento di Agraria, University of Sassari, Viale Italia 39, Sassari 07100, Italy \\ * Correspondence: lis.armendariz@gmail.com (V.A.); armenia@dis.uniroma1.it (S.A.); \\ Tel.: +52-181-24359855 (V.A.); Tel.: +39-333-8711021 (S.A.)
}

Academic Editors: Giaime Berti, Moya Kneafsey, Larry Lev, Irene Monasterolo and Sergio Schneider Received: 31 August 2016; Accepted: 17 November 2016; Published: 7 December 2016

\begin{abstract}
The world is continuously transforming to supply growing cities and urbanization processes are still driving important changes in our current food systems. Future sustainability constraints are emphasizing that Food Supply and Distribution Systems (FSDS) are deeply embedded in city-region systems with specific technical and socio-ecological characteristics. This paper aims to provide a systemic understanding on FSDS focusing the integration of urban and rural structures considering the system biophysical boundaries and societal targets. A qualitative framework model, based on the Food and Agriculture Organization of the United Nations (FAO)'s FSDS literature, has been developed by using Systems Thinking (ST) and System Dynamics (SD) approaches. The model analysis suggested that to increase sustainability and resilience of food systems large emphasis has to be maintained on: (i) estimation of local territorial carrying capacities; (ii) land use planning to enhance connections among rural supplies and city needs; (iii) city policies, to regulate emergent market size and local scale of production; (iv) technological efficiency at farm, distribution and market levels; (v) urban, peri-urban and rural functional linkages that considers social metabolic balances; (vi) rural development as a core point for building sustainable food systems and counteracting the urbanization growth. These key areas are relevant to test new paths of cities-regions reconfiguration towards the transition to resilient agri-food systems.
\end{abstract}

Keywords: food supply and distribution systems; resilient food systems; resilient cities; sustainability; systems thinking; system dynamics; self-organizing systems; food systems governance; societal metabolism; city-region governance

\section{Introduction}

The world has been continuously transformed in order to supply growing cities with their basic needs and food security. The World Food Summit [1] defined food security as when all people, at all times, have physical and economic access to sufficient, safe and nutritious food to meet their dietary needs and food preferences for an active and healthy life. In the past the main actions to fill the food security gap have been focusing, at farm level, on pushing an increase in the scale of production as well as in crop production levels, on the intensification of food hubs and logistics, and on the reduction of prices to assure the food commerciality. Large importance has been given to world trade 
dynamics of food commodities and prices so that global arrangements are prevailing by stressing local environmental equilibrium and social structures. These transformations are performed via urbanization processes, traditionally considered equivalent to development. Urban and regional food needs are strictly connected to the issue of correctly managing Food Supply and Distribution Systems (FSDS), which are embedded in cities-regions systems who, in turn, are characterized by growing urbanization trends, in turn impacting back on the FSDS functioning.

Narrowed food systems policies often aim at increasing size of food systems infrastructure related to food systems and are pushed by private investors' expectations [2]. Complex systems decision support tools, like mathematical and conceptual models should be developed and applied to assess the pertinence, effectiveness of such policies [3]. Models might offer the opportunity to assess future policy effects while considering, among others, the policies' impact on infrastructure and socio-ecological characteristics of complete regions.

Specifically, qualitative framework models are able to describe and highlight the latent structure of a system and predict the future system behavior [4]. The system structure can be determined by describing the connections among the main system components, which are often chained in multiple feedback loops. In fact, systems do not work the way we think, they tend to be counterintuitive [5]. The analysis of the feedbacks, conceptualized through Causal Loop Diagrams (CLD), characterizes a certain system and is helpful to describe the main rules of the system organization and to predict the future behavior of the system [6]. Under specific conditions, the dominance of a certain loop in respect to the others throughout a certain time interval determines the behavior of a system in terms of shape of its pattern. The presence and identification of the feedback loops allow to qualitatively forecasting of future trends. Considering the structure of the FSDS a qualitative analysis might be further used as a basis for quantitative dynamic models to support the FSDS functioning understanding and design policy scenarios. A primary systemic perspective to analyze the urban food systems structure can be developed using Systems Thinking (ST) and System Dynamics (SD) approaches. ST and SD are iterative process to get a better understanding of the system [6]. Drawing causal maps or CLD using $\mathrm{ST}$ and SD approaches is a technique for mapping the existence of the feedback within and across interacting subsystems. The modeling process demands the identification and definition of problems, the overall system conceptualization and the qualitative modeling, which often impact our initial system understanding. ST and SD can support designing better Urban Food Policies to analyze the urban food systems structure because both phases enhance the insights elicitation and increases the likelihood of performing a good policy analysis.

\section{A System Understanding of Food Supply and Distribution Systems (FSDS)}

Providing insights for policy creation requires a thorough understanding of the nature of the systems we are dealing with. Cities and regions constitute the environment where FSDS are embedded. Urbanization drives the city growth and represents specific consequences in determined cities-regions systems due to its high impact on the economic structure, population composition and size, ecology and landscape of the territories where it takes place [7].

Understanding the city and region characteristics and mechanisms of change is relevant to achieve a system perspective on FSDS. In order to build on that systemic understanding this section will provide a brief literature review of cities as self-organizing systems and a possible explanation of their evolution, an example of system approach to understanding urban settlements called Socio-Ecological Infrastructural Systems [8], and it will finalize with the presentation of a framework model to understand specifically FSDS from a system dynamics (SD) perspective.

\subsection{Cities and Regions as Complex Self-Organizing Systems}

The first notions of the city as a system were developed in the 60 's. The city as a system was understood as elements interacting among them through structures characterized by feedbacks within certain boundaries [7,9-11]. The recognition of interactions and feedback structures while observing 
the city provides important insights still not widely considered in policy innovation. One of these insights is the attention to the self-organizing characteristic of cities and regions.

Urban systems, or cities, are self-organized subsystems of wider systems, whose interactions between different parts determine macro-areas or regions within the macro-system. The behavior of such areas is relatively autonomous among them, and possesses specific dynamics, which distinguish one from the other [12]. At the same time, within the urban systems there are other subsystems-i.e., social, economic and territorial-which have lower self-organization structures: this is the case of FSDS.

The general pattern for cities' growth is via the urbanization processes. Even when it is a general pattern, the world cities present different characteristics in their development and growth. Several studies have demonstrated that specific historical events in urban systems are required to understand the size, distribution and infrastructure development, which affect the "universal change" from rural isolated areas to diversified, concentrated and hierarchized urban settlements. [11-13]. A similar explanation is provided in Allen [11] referring to the rank size rule by [14] about the interaction of urban settlements where explanation of growth is economic competition and another is the appearance of industrial satellites and wealthy housing buildings attracting population. When population increases, infrastructure innovation and transportation improvements attract people from the surrounding villages. The urban areas grow even faster and keep interacting with the larger settlement. The smaller ones stay out of the relation with the big urban settlements. The transformation dynamics from rural to urban discussed previously has important consequences in the development uniformity of regions. This diversity represents a challenge for a single FSDS policy framework, however structural patterns can be identified.

\subsection{Cities as Socio-Ecological Infrastructural Systems (SEIS)}

Cities are embedded in wider systems, which are ecosystems regions where human and ecological sphere interact making a single system. One recurring error when dealing with environmental issues is treating human and ecological systems as separated contexts. Socio-ecological systems (SES) are complex systems and inherently behave in non-linear ways, are strongly coupled and display "thresholds" in their dynamics [15]. Considering them as linear, predictable and controllable systems also leads to policy failures. Thus, more integrative perspectives are increasingly required.

Among several perspectives to understand urban settlements we found the Social-EcologicalInfrastructural systems (SEIS), which implies the integration of relevant disciplines for the study of cities as systems towards sustainability. Among disciplines considered in SEIS approach are: Urban Metabolism, Industrial Ecology, ST Environmental sciences/climatology, Infrastructure Engineering, Architecture, Public Health, Public Affair, Behavioral Sciences and Urban Planning. SEIS approach, in contrast to the SES perspective, considers the links between natural systems, engineered infrastructure, actors, and institutions.

A representation of the SEIS approach is provided in Figure 1, which considers: (a) the integration across the spatial scale; (b) multi-scale risks posed to cities by infrastructure-environment interactions; (c) examples of institutions that shape energy use and greenhouse gas (GHG) emissions.

While studying the mechanisms of change of urban settlements, it becomes clear that infrastructural and technological systems play a role on transforming the biophysical system supporting the cities functions. Those infrastructures are exactly who play a fundamental role in the kind of ecological transformation, economic identity and growth of a city. Those urban infrastructures are tied to different scales of stakeholders, and are those who determine the rules of the SEIS [8].

An illustration of the different intervention scales in an urban system is provided by the SEIS framework (Figure 2). 
a)
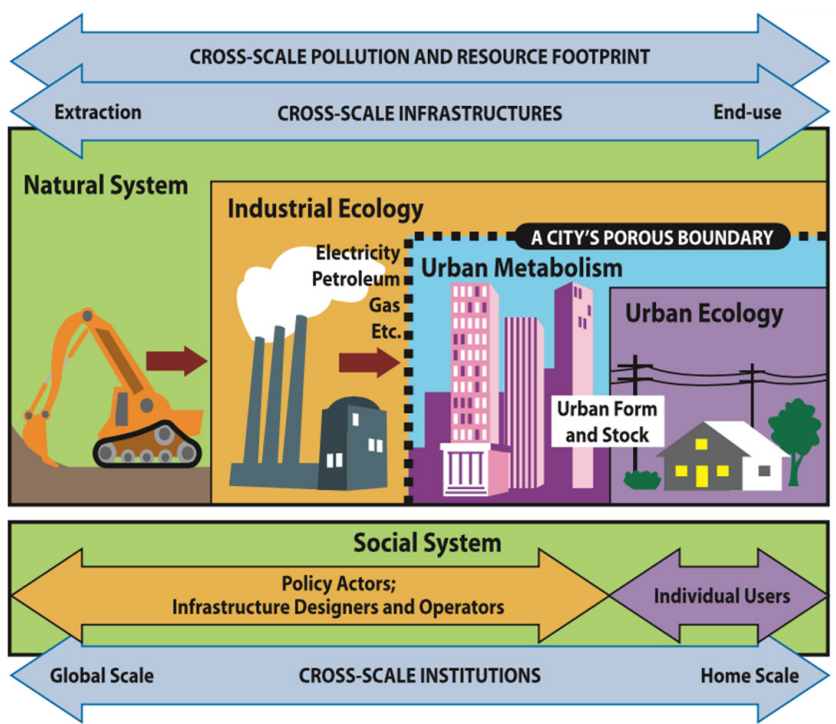

b)

\begin{tabular}{|l|c|c|c|}
\cline { 2 - 4 } $\begin{array}{c}\text { Global climate } \\
\text { change }\end{array}$ & $\begin{array}{c}\text { Regional air pollution: } \\
\text { Climate constraints on water supply }\end{array}$ & $\begin{array}{c}\text { Urban heat } \\
\text { island }\end{array}$ & $\begin{array}{c}\text { Indoor air } \\
\text { pollution }\end{array}$ \\
\hline Global Scale & MULTI-SCALE RISKS & Home Scale \\
\hline
\end{tabular}

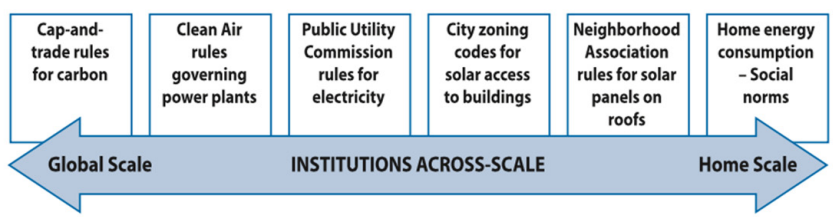

Figure 1. Social-ecological-infrastructural systems or SEIS [8]. It represents: the integration across the spatial scale (a); multi-scale risks from infrastructure-environment interactions (b); examples of institutions that shape energy use and greenhouse gas (GHG) emissions (c).

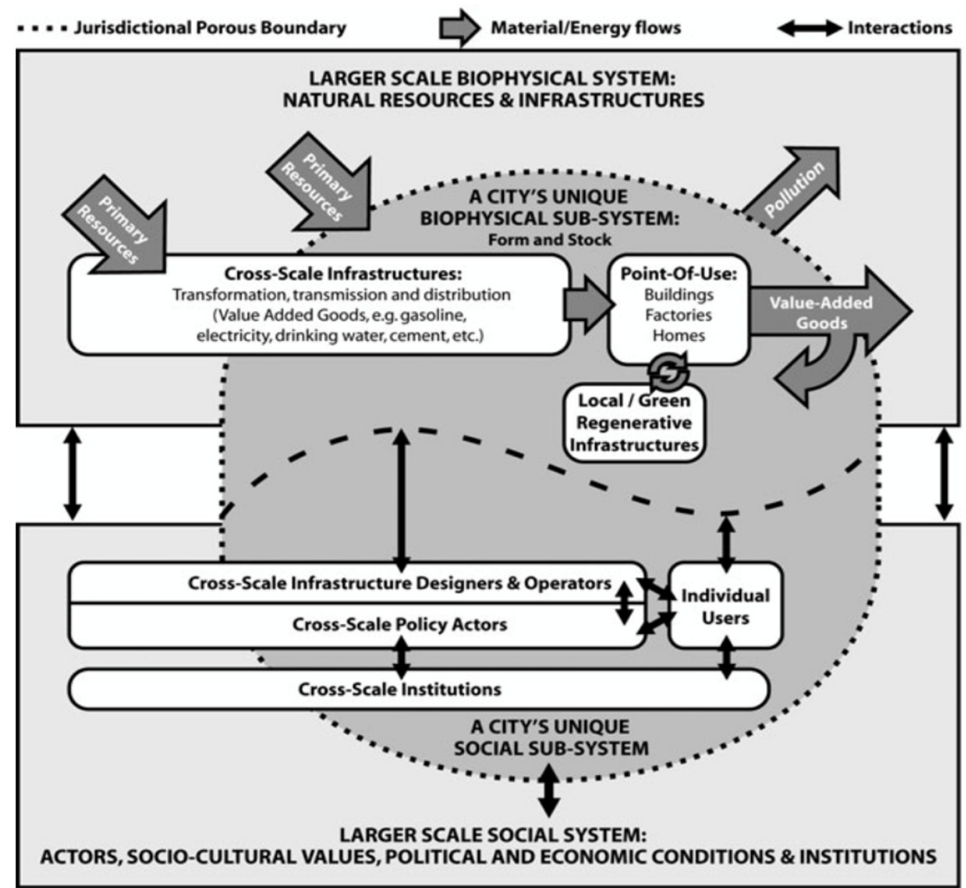

Figure 2. Schematic representation of the social-ecological-infrastructural systems or SEIS [8]. 
Urban and households scales present clear jurisdictional or administrative boundaries, thus he stakeholders of each scale are diverse. The material and energy inflows come from the biophysical system, the environment, which is considered in the global or larger scale. Pollution and consumption flows are part of the industrial and human activities belonging to lower system scales and are determined by the type of existing infrastructures $[8,16,17]$. An important scale while searching for new governance of urban issues is the attention to the second larger scale, represented in SEIS framework as the social system scale where intangible variables such as values, mental modes, principles shaping institutions and their conditions take place.

Understanding how a system works requires an appropriate approach through which the system is observed. System Dynamics philosophy [18] states that in order to understand and possibly, solve a problem you should not make a model of the specific system your problem belongs to, but a model of the family of systems to which yours belong. So far, in Sections 2.1 and 2.2, we have been able to understand that urban issues are food system issues. The particular development of urbanization, which is the change of rural to urban settlements, in determined zones characterize regions. Frameworks such as SEIS were currently adopted in order to capture the multi-scale nature of urban settlements where FSDS are embedded.

However, identifying the food systems environment in nominal terms is not enough for understanding its functioning nor design policy. Therefore, the next section contains a framework model which explains the feedbacks characterizing the food systems structure in city-regions systems, considering the main items composing those.

\section{Objective}

The objective of this paper is to provide a system understanding on FSDS by: (1) studying the mechanisms regulating food systems at the urban and regional level; and (2) presenting a general qualitative framework model for FSDS understanding. This framework was obtained by the application of a ST and SD approaches to the food system's structure analysis. The system understanding on FSDS is expected to:

- Build on the discussion of food systems as self-organizing systems and on the urbanization consequences on food systems and on the resilience regional food systems resilience.

- Support the opportunities identification of FSDS policies suggested by FAO.

- Highlight key points towards a FSDS policy creation based on relevant issues of food systems, which besides the production and distribution process and markets structures, are dependent on the cities and regions structures in which FSDS are embedded.

The proposed FSDS framework model was elicited from the critical study of FAO's technical documents on FSDS, directed to decision makers, and from further research on food systems' structure [2,19-24]. The opportunities of the policies suggested by FAO are analyzed in the light of the insights coming from the proposed FSDS framework model. Likewise, key points towards a regional policy creation are provided, some of which build-up on the discussion between the desired infrastructure growth and regions resilience, also determined by their local rural and urban food systems.

\section{Methodology}

The general FSDS framework model and policy considerations proposed in this work have been elicited through the following process:

- The development of an epistemic ground to understand FSDS assessing their characteristics and properties as complex systems, in order to evaluate the feasibility of using complex system methodologies to analyze them [25]. 
- The analysis of the document from the Food and Agriculture Organization of the United Nations (FAO) "Studying Food Supply and Distribution Systems to Cities in Developing Countries and Countries in Transition-Methodological and Operational Guide (Revised Version)" [22] what we call "FAO's Framework for FSDS Analysis" (FFFA) and other documents from the Food into the Cities collection using ST and SD approaches. This analysis includes the identification of the main stocks, flows, relevant variables and the system's boundary of FSDS according to FFFA, the generation of system archetypes analyses, and the qualitative characterization of FSDS by two group model building sessions with FAO experts which resulted in an extended qualitative FSDS model presented in Armendariz et al. [26].

- The re-conceptualization of the extended qualitative FSDS model previously mentioned by simplifying, in a revisited FSDS framework model (Figure 3), its general structure and characterizing and analyzing the expected dynamics.

\section{A Critical Review of Literature on Cities and Regions as Self-Organizing Systems in Which Urbanization Is the Dominant Trend. Results: FSDS Framework Model}

The FSDS framework model presented in the previous paragraph (Figure 3) consists of a Causal Loop Diagram (CLD), which is characterized by a system dynamics/systems thinking representation of the wider systemic structure where FSDS are embedded. System Dynamics (SD) is a methodology that supports and enhances systems understanding through the recognition that the system structure is responsible of the system behavior. The convention for drawing a CLD consists of a set of variables connected by arrows denoting causal influence with a given polarity, to indicate how the dependent variables change with respect to changes of the independent variables $[6,27,28]$. The loops generated by the variables connection are labeled with a name, related with the loop role in the system, and a polarity (+or - signs). A positive sign (+) means that the change effect of the independent variable on the dependent one is positively related, i.e., if one increases so the other does. A negative sign (-) means the causal effect of change is negative among the two variables, i.e., the increase in one variable represents a decrease in the other. There are two kind of loops which are studied on the basis of their characteristics: (1) Reinforcing: self-reinforcing loops, which imply that if they were the only loops operating in the system, or if they are the dominant loops, they grow exponentially; (2) Balancing (B): self-correcting loops which counteract change.

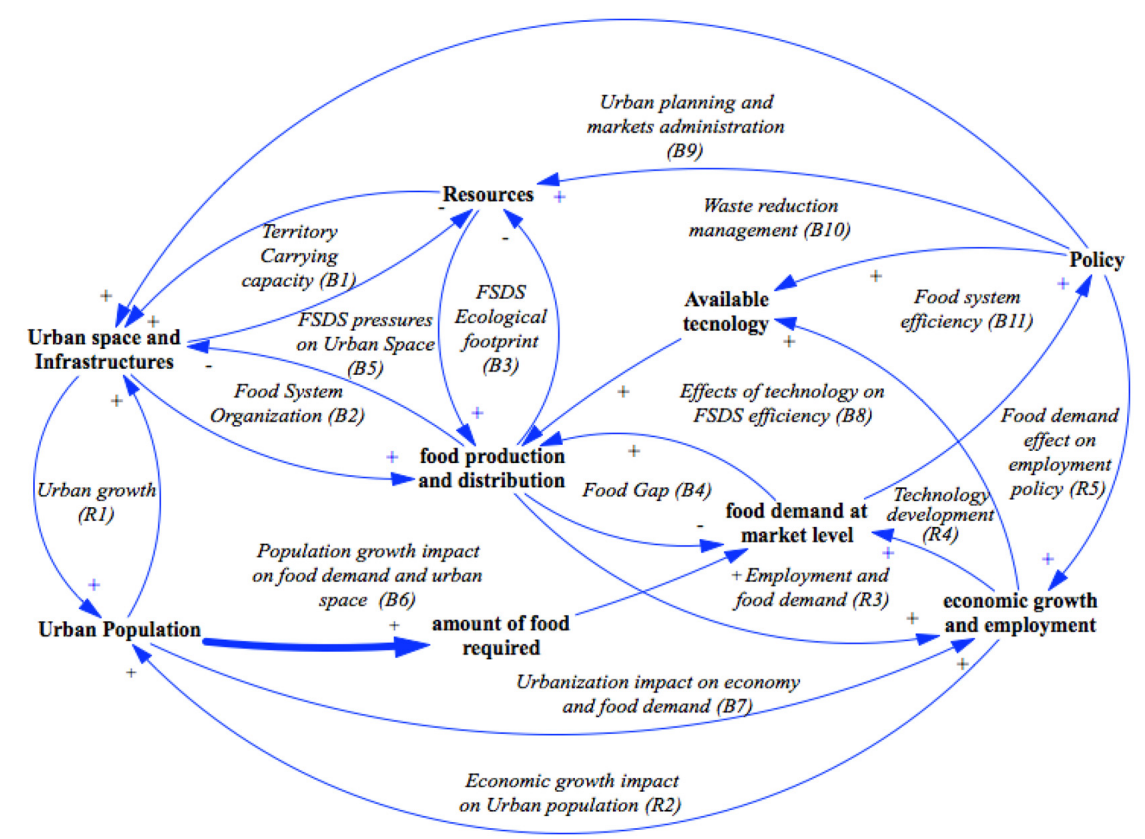

Figure 3. FSDS framework model adapted from Armendariz et al. [29]. 
Note that, in Figure 3, a positive causal effect of the independent variable change on the dependent variable is showed by a positive (+) on the arrow end, i.e., when independent variable increases or decreases, the dependent variable changes in the same direction. The negative sign $(-)$ on the arrows mean that the causal effect among independent and dependent variable is negative, i.e., when independent variable increases the dependent variable decreases. The bold blue arrow represents FAO's guide main question: "how to meet urban food needs of a growing population?" The feedback structures (or "loops", named after their polarity as B, for balancing, and as R, for reinforcing) were identified and named according to their function in the system.

Our framework model is focused on providing a system perspective to FSDS considering the mechanisms featuring city-region systems. Although as explained in the previous chapter, each city-region system has a particular development determining its size and characteristics, the following feedback loops explain the basic system structures responsible of city-regions change studying the relation between urbanization, infrastructure, technology and economy development, resources consumption and population size. Overall, this framework shows how FSDS are embedded in that wider systems context, are part of those systems providing feedback and are also limited by those. The relevant feedback structures for FSDS are described in the following sections: in some of them we will find ground for exploring a few food policy strategies.

\subsection{FSDS Reinforcing Feedback Structures}

The feedback structures are following listed and explained:

(R1) Urban growth system loop: represents the feedback between urban population and urban space, which is a self-reinforcing relation. Urban population growth increases the need of new infrastructure and urban space, the urban growth at the same time functions as a population attractor. This relation impacts the urban geographical boundary by the land use change from rural or peri-urban territories becoming urban land.

(R2) Economic growth impact in Urban Population loop: explains another self-reinforcing dynamic relevant for urban growth, the economic growth in cities increases the migration rate from rural population; more population means labor destined to economic activities and urban population revenues from paid work. The urban growth has an impact on natural resources, which are reduced as the urban space and infrastructures increase. This impact can be noticed in the land use change, pollution or change on available non-renewable resources.

(R3) Employment and food demand loop: Food demand at the market level is limited or boosted by the economy and job dynamics, food system business revenues provide economic growth, employment opportunities out of the economic growth provide income to people so to demand food at market level. Here it is important to notice that urban population is one of the main food demand drivers, which is understood as the amount of food people look for in formal markets. As food demand depends on different factors (total population, income level and food provided by supply and distribution chains) it should not be confused with the absolute amount of food needed which rather is an indicator of the food requirement per capita multiply by the total population.

(R4) Technology development loop: shows the indirect effects of food market in economic growth and technology improvement.

(R5) Food demand on employment policy loop: explains how people income is directly related to the amount and quality of food consumption. Food demand is different to actual amount of food required in a city. Thus, the socioeconomic conditions determine people capability of using income to satisfy their food needs, therefore, a sound urban food policy should aim to reduce urban poverty levels. Economic growth and employments, which translate in people's income, are needed achieve access to food. 


\subsection{FSDS Balancing Feedback Structures}

(B1) Territory carrying capacity loop: represents the system limit to growth. In fact, urban growth is no longer possible if the resources needed for that growth—for instance, land available for infrastructure-are over.

(B2) Food system organization loop: represents the relation between urban space for markets and the food logistics and consists of a balancing loop. In fact, the limited urban space impacts on the available space for markets allocation and distribution processes. In addition the scarceness of this resource creates competition among food and other activities. Land dedicated to any other urban issue means less land for markets and roads. At the same time, in the long-term more roads increase urban agglomerations affecting distribution processes.

(B3) FSDS Ecological footprint loop: is explained by the environmental impacts of food systems; the increase on food production, processing, distribution and consumption activities implies renewable and non-renewable resources use and pollution.

(B4) Food gap loop: represents the relation among food demand at market level and the food production and distribution system. We could say that food production and distribution activities reduce food gaps, i.e., the difference between the production and consumption, at market level by increasing the food availability. However, food production and distribution management deficiencies or a crisis in the system might decrease the food supply of cities and increase the food gap.

(B5) FSDS pressures on Urban Space loop: is the system structure summarizing the last three system loops, which indicates that the food system activities are only possible after the urban space use and this after the resources use, including non-urban land and non-renewal resources. The resources competition relation of food systems with other urban needs (i.e., infrastructure, industry) leading to a resources overconsumption represents a risk not only for the food system activities, but for the urban system itself.

(B6) Population growth impact on food demand and Urban Space loop: represents the food demand out of the population change boosting food production and distribution processes, which at the same demand urban space and infrastructure translated in urban growth that attracts population.

(B7) Urbanization impact on economic growth and food demand loop: is an external loop found after capturing the population impact on economic growth. Employment increases income to demand food, the economic growth increases urban growth, which will boost the food production and distribution process that will compete with other industries and households for space and infrastructure.

(B8) Effects of technology on FSDS efficiency policy loop: the food supply chain efficiency improvement depends on the organization and the technology levels applied to food production and processing.

(B9) Urban Planning and Markets Administration policy loop: considers key areas for policy intervention related to urban space management and innovations, density, congestion, adequate roads and a city planned allocation of formal markets and informal markets according to urban population distribution rendering their socioeconomic.

(B10) Waste reduction and management policy loop: these kinds of policies can improve the supply chain efficiency and reduce pollution. B10 and B11 structures represent balancing feedbacks aim to increase food supply by tackling inefficiencies and negative environmental consequences, and to reduce the urban food gap.

(B11) Food systems efficiency policy loop: food system efficiency can be boosted by increasing the technology level used in food production and processing activities. The natural resources consumption (land, water, energy, raw materials) is strongly related to supply chains efficiency, consumers' life style and waste disposal processes.

The FSDS framework provides, in a simplified way, the structure of the dynamics between land, population, food distribution and production processes, resources, technology and economy and employment. This systemic view shows that increasing the efficiency of the food production and distribution (production, assembling, handling, processing, packaging, transport, storage, wholesaling 
and retailing) could lead to increasing the food supply to cities, reducing costs and wastes. However, it also shows that increasing food supply to cities does not imply automatically meeting the food requirement per capita. Socioeconomic conditions such as the prevalence of poverty which is a topic considered in the goal but absent from FAO's policies suggestions, ecological conditions as the availability of resources, urban conditions such as land availability, urban space and infrastructure are non-food issues relevant for the urban FSDS functioning and with high impact on food security.

General key-points elicited using SD on the FFFA [26] critical study are the following:

1. The FSDS mechanics are embedded in the field of Urban Dynamics: population, infrastructures growth and urbanization highly impact the FSDS organizational capability to provide food.

2. Conceiving population growth as the main problem in effectively feeding cities (thus given the raise in food demand) is only one part of a bigger picture and does not bring any information on solving the problem. The way most cities are conceived and structured is what contributes to the system being unsuccessful on meeting urban food needs.

3. Supply and Distribution Systems are just a part of a wider system. Urban, rural and peri-urban dynamics cannot be longer treated in isolation if the aim is to meet population food needs for the next decades.

\section{Policy for a City-Region FSDS Governance}

In the previous chapter, we have discussed the complexity in which FSDS are embedded. The ST and SD approaches applied to the FFFA resulted useful to explain the importance of overcoming the focus on the urban population growth as the main FSDS problem without being critical to way the cities are structured. Urban population increase represents a pressure on the system to provide food, yet, the urban dynamics closely related to the urbanization and its consequences highly impact the natural resources (land, water, production and distribution assets on which FSDS depend) and are this urbanization paradigm what keeps pushing the increase of urban population. FSDS functioning is facing structural limits (i.e., land, resources availability) and operational challenges (i.e., pressure of congestion on distribution processes). Currently, science brings us some tools to approach better policy making while holding a system perspective on the issue and using simulation tools. Yet, we have been also able to grasp the uncertainty in which decisions are made due to lack of information or to the evolutionary nature of systems we inhabit and reproduce [29-31].

The application of complex system methodologies brings the possibility of achieving better policies especially when facing high levels of complexity and uncertainty. The complexity rises when considering simultaneous scales and different kinds of systems interactions into the analysis of the problem to be tackled. According Walker et al. [32] the uncertainty is given by the rapid changing environment, in front of inadequate information (unreliable, inexact or simply still unmanageable). However, a decision maker with plenty of quality information but lacking of system's understanding will have a hard time solving a problem and is in risk of wasting resources into a solution which will work only in the short-term or which will be resisted by the system [6]. Modeling and simulation allow for complex systems analysis, coherent with the nature of our social systems, and policy experimentation and testing in virtual environments, scenario development for risk assessments or for long-term planning. Model-based decision making, in front of traditional decision methods, has the potential of bringing forward a new generation of policies based on comprehensive system analysis and by, among others, building transparent models for a wider range of stakeholders, boosting also the accountability on decisions taken [33]. The next section contains policy insights elicited from the ST and SD approaches to the study of FSDS and the other macro-systems where they are embedded: city and the region. Those are recommended to be considered while building a regional governance mechanisms and policies to satisfy the food agenda of urban systems. 


\subsection{Key Points Towards a FSDS City-Regional Policy from a System Perspective}

\subsubsection{Structural and Operational Issues}

As we have elicited from the FSDS framework model analysis (Section 5), there is a wider systems context impacting FSDS activities. FSDS processes are limited or boosted by other "non-food" issues. There are two kinds of issues important to distinguish while thinking in FSDS improvement to meet food needs:

- Structural issues: are part of the cities structures and the macro-systems constituted by regions, where water, land availability, population, infrastructures, laws, economic systems constitute the FSDS functioning structural limits.

- Operational issues: part of the FSDS and cities subsystems, which are mainly FSDS and public institutions administrative processes and management issues.

A key point should be to focus on policy objectives related to the FSDS structure. Addressing only operational issues is short-sighted and risky. The extended FSDS qualitative model [26] and the FSDS framework model (Figure 3), show how urbanization is a reinforcing feedback-loop, which high impact the environment and resources on which FSDS run. Additionally, it shows how food processing and distribution activities, understood as operational issues, are just a part of all the subsystems interacting which impact the goal of meeting urban food needs. As a conclusion from the systems analysis performed, it was found that improving the efficiency and food production and distribution process does not imply automatically meeting urban food needs. Other subsystems such as the biophysical, economic, territorial, infrastructure frame the capacities of FSDS.

Currently mainstream policies focus on operative issues of FSDS. FAO's policies are an example of the lack of intervention in the structure where they are embedded. As we have discussed in Section 2, policies focused on operative issues will be always limited in front of structural pressures, for example, building more roads to decrease congestion might be useful in the short run, yet, if population, which is a structural issue presents an exponential growth and the city space is limited, this operational solution will fail in the medium term. Analyzing the change over time of the structural issues of FSDS, considering the expected change in stocks could be information useful to set policy targets or limits of growth. Another hint is to try to keep those stocks sustainable over time and find equilibrium states in the systems. Simulation tools could support the equilibrium points' findings of joint policies aiming at improving structure and operational issues.

Ignoring structural limits, going for growth without a reviewing the carrying capacity of the system will end up affecting the resilience of cities [34]. The stakeholders involved in a decision should depend on the structural or operational nature of the issues to address.

\subsubsection{Scales of Intervention}

Achieving certain goal in an urban food system will depend on the particular conditions that food system and the systems related. Different scale of interventions might be needed to achieve urban food security targets [35]. Each scale implies specific stakeholders, legal frameworks, ecological, economic, cultural, social conditions, among others.

FSDS relevant intervention scales and examples of issues related to each scale are:

- Global: international and planetary issues. New international economic agreements, transnational companies' laws or behavior, climate change, desertification, water availability are example of issues at this scale.

- Regional: extended territory. Some national or country issues fall in this scale intervention. However, this scale exceeds traditional national boundaries and considers part of the macro-system where economic, biophysical issues, migration trends, rural development would be the focus. Illustration issues at this scale involve the B3 Ecological food print, B1 Territory 
carrying capacity, B7 Urbanization impact on economy and food demand feedback structures from the FSDS framework model (Section 5, Figure 3).

- Urban: city related systems considering the city infrastructure planning, technology, and administrative and institutional issues. R1 Urban Growth, B5 FSDS pressures on Urban Space, B9 Urban Planning and Markets Administration feedback structures from the FSDS framework model are examples of issues belonging to this scale.

- Local: municipalities and localities (neighborhood) systems where social norms, shared activities or processes, local infrastructures are relevant. An example of an intervention at this scale level is an employment program implemented at municipal level which impact the R3 Employment and food demand feedback loop from Figure 3.

- Individual: related to personal choices, preferences and the consumption habits out of education level, socio-economic status or culture issues. This kind of intervention can be illustrated by the impact on the demand of certain product due to the sum of consumers' individual decisions, for instance, the meat demand can be decrease due to an education program on the ecological consequences of meat consumption. The change in meat demand would impact the variable "food demand at market level" of that specific product, eventually with the possibility of having an impact on B4 Food gap loop structure, always considering only what concerns to the product on which consumers made the consumption decision.

As we can observe, the FSDS framework model presented in this work (Figure 3) is a simplified representation of the FSDS detailed model [26]. The high aggregation level of this work shows the regional and urban scales more clearly. The global scale was not included in the FSDS framework model as it was not reported in FAO's guide for decision makers [22]. The FSDS framework model proposed within this work is rather a generic model. In the case of FAO's policies, which will be further explained in the next section, the intervention scale proposed is "local". From the FSDS framework model (Section 5) we can start envisioning the level of intervention required to implement policies, i.e., interventions at local scale might have financial, administrative, territorial limitations in order to address a required structural issue. All the same issues such as knowledge, information channels, capital and tools are transversal and useful at any scale and can be implemented and highly supported at local scale.

\subsubsection{Stakeholders}

Municipalities' local authorities are considered the most relevant actors for improving the efficiency of food systems efficiency by FAO. Yet, FSDS framework model (Section 5) has allowed us to identify among structural and operational type of issues and the diverse nature of issues involved in meeting food needs, which per se involve different kind of actors. Therefore, this section will focus on discussing: (1) who are the relevant actors in FSDS? and (2) how to improve the efficiency of those actors?

In order to respond to the first question, the SEIS framework [8] considers three specific types of stakeholders relevant at urban level: (1) Individual users: represent households and businesses within the city whose demand for water, energy, and resources results in the commissioning of infrastructures serving cities; (2) Infrastructure designers and operators: are responsible for the infrastructures design, operation, maintenance, and dismantling; (3) Policy actors: include elected, appointed, and civil government officials, citizen groups, scientists, journalists, special interest groups, and coalitions who attempt to shape the processes and outcomes of infrastructure governance.

Municipalities' local authorities, the most significant according to FAO, are stakeholders with certain important roles. Yet, SEIS framework suggest important urban actors, which from a system perspective on FSDS, should be also considered beyond the common FSDS operators (among them consumers, wholesalers, retailers, producers, urban planners and regional planners, national decision 
makers, transnational companies and international organizations) are also part of the stakeholders to be considered.

The second question of this section is related to governance issues: how to improve the efficiency of those actors? The acknowledgement of cities and regions as self-organizing systems opens the perspective of a whole new set of actors whose goals, activities, technology, culture, capital and rules define the urban structures. Cities and regions as self-organizing systems imply an autonomous behavior of their agents on a determined space under specific conditions. As described in Section 2.2, the agents in the system might not be aware of (a) the possibility of knowing how the system can change; (b) which is the optimal solution; (c) information on the system complexity; and (d) the possibility of controlling decisions of other relevant stakeholders. Bertuglia and Vaio [36-38] propose the assisted self-organization concept, which means that certain external supervision under an order principle has to be active in the autonomous adaptation capacity of the systems individuals and organizations. Such order principle can potentially be embedded in cities new structure design or in rules under which agents work. In this case, such new rules can work on economic, social fields or be communicated via learning or educational processes to understand in better way their role in FSDS embedded in urban environments with specific external and internal constrains.

\subsubsection{Production and Consumption Balances}

The search for efficiency of current FSDS structures might be doomed due to the impossibility of keeping certain material standards of industrial production and households consumption in front of the growing pressures such as population (illustrated by the feedback structure R1 Urban growth of FSDS framework model, Figure 2), pollution or waste at the same time dependent on limited-resource based processes (represented by the B1 Territory carrying capacity feedback loop, Figure 3). Intervening on food systems should take into account regional ecological boundaries and the sustainability of the current standards of consumption related to food, energy, water of cities and food production locations [39-41]. One way of designing new agri-food chains linking production and consumption places more efficiently is applying the viability checks $[16,17,41]$ from urban metabolism approaches in order to evaluate if the system is able to produce what consumes, considering the energy and material flows involved in all processes. Disregarding the consumption and production balance will keep cities away from possible equilibrium states [41].

The system perspective of FSDS reported in the previous chapters and the key points for policy creation reported in the following sections provide elements to understand and analyze FAO's FSDS policies. A quantitative modelling of the framework might complement the performed analysis. The translation of the framework in stock and flow diagram using SD techniques [42], the parameterization of the connections using empirical data will allow to analyze and study the target system from a numerical pint of view. To reduce the gap among food demand and food availability in a city and perform policy experimentation, the starting point from a modeling point of view, should focus the integration of (a) the population growth within the urban dynamics oriented to FSDS efficiency and; (b) the rural supply capacity under environmental and anthropogenic constraints.

\subsubsection{FAO's FSDS Policies Opportunities}

In order to understand the policy advises proposed by FAO, the documents of the Food into cities collection were classified and analyzed [26]. This search helped clarifying FAO's competence in the solution and identifying what actions could be useful for decision makers and are deemed as possible for FAO itself. FFFA considers relevant aspects to improve FSDS the following: (1) Description of supply and distribution agents' needs (producers, wholesalers, retailers, market administrators and consumers); (2) Limitations, instruments and needed collaboration efforts of municipalities and local authorities to solve difficulties faced by the FSDS agents; (3) Role of the urban planners supporting the urban and peri-urban supply, describing their intervention scale and actions. 
Based on the linear understanding of FSDS, FAO provides decision makers of developing countries and countries in transition policy guidelines aiming meeting urban food needs. The classification on 40 policies suggested in FFFA based on their recurrence (Table 1) showed as key issues: Understanding and planning of FSDS (15 out of 40 policies), Law enforcement (14 out of 40 policies), Urban infrastructure, construction and maintenance (11 out of 40 policies). Some low-recurrence policies are instead: Social issues (1 out of 40 policies), Stakeholder collaboration for the improvement of FSDS ( 1 out of 40 policies), Public administration role in FSDS ( 2 out of 40 policies). Other policy topics referred in the documents are: Environmental issues (4 out of 40 policies), Health \& Nutrition issues (5 out of 40), Budget or capital levying from FSDS activities (5 out of 40), Participation (dialogue with stakeholders) for public policy (4 out of 40), Interventions in the food market activities ( 3 out of 40), Information and education activities (4 out of 40). In addition, other classification of policies are highlighted: law enforcement policies (14 out of 40); policies related to information and education issues (4 out of 40); participation and dialogue to build public policy (4 out of 40); stakeholders collaboration for improvements of FSDS (1 out of 40); public administration clarification roles ( 2 out of 40 ); understanding and planning of FSDS (15 out of 40 ).

As in FFFA there is no direct reference to a priority problem, the policies proposed (available in Table 1), belong to different nature of issues, intervention scales and stakeholders' responsibility. In addition, there is no method suggested for policy testing or prioritization and to perform the 10-year recommended scenarios. 
Table 1. Five main roles from municipalities to solve food insecurity of low-income urban households [23] adapted from Armendariz et al. [26].

\begin{tabular}{|c|c|c|c|c|}
\hline $\begin{array}{l}\text { Promote Supportive Policies } \\
\text { towards Agents * in FSDS ** }\end{array}$ & Promote Private Investment & Intervene in Food Supply and Distribution Activities & $\begin{array}{l}\text { Coordinate Public Interventions } \\
\text { and Private Initiatives }\end{array}$ & $\begin{array}{l}\text { Intermediate between } \\
\text { Central Government and } \\
\text { Private Food Sector }\end{array}$ \\
\hline $\begin{array}{l}\text { Policy-makers' awareness to the } \\
\text { needs of agents of FSDS (12) } \\
\text { Involvement of FSDS agents in } \\
\text { policy formulation and } \\
\text { implementation (9) } \\
\text { Decision makers understanding } \\
\text { on how to improve FSDS (12) })^{* * *} \\
\text { Strengthening representation of } \\
\text { private associations on planning } \\
\text { implementation (9) } \\
\text { Dissemination of policy goals } \\
\text { and objectives (8) } \\
\text { Mission fulfillment and open, } \\
\text { communicative and efficient } \\
\text { behavior (9) }\end{array}$ & $\begin{array}{l}\text { Promoting rules and private } \\
\text { sector responsibilities }(7) \\
\text { Ensuring that norms and } \\
\text { procedures are in line with } \\
\text { investors' expectation and } \\
\text { capacity }(6,7) \\
\text { Enforcing laws, specially about } \\
\text { contracts }(6,7) \\
\text { Providing basic infrastructure } \\
\text { facilities and services }(2,7) \\
\text { Ensuring adequate } \\
\text { management of utilities } \\
\text { companies }(6,7) \\
\text { Ensuring efficient land, real } \\
\text { state markets and land tenure } \\
\text { security }(6,7)\end{array}$ & $\begin{array}{l}\text { Planning } \\
10 \text { year forecast of land and production factors }(1,3,12) \\
\text { Identification of poor urban households }(1,12) \\
\text { Land use plans }(2,12) \\
\text { Provision of land tenure security and safe water }(2,5,12) \\
\text { Prepare rural-urban transport plans }(2,12) \\
\text { Design food market and processing } \\
\text { infrastructure }(3,2,12) \\
\text { Information } \\
\text { Food hygiene and nutrition rights }(5,8) \\
\text { Agro-inputs and chemicals use, safe solid waste }(4,8) \\
\text { Infrastructure facilities and services } \\
\text { Define markets infrastructure needs and } \\
\text { slaughterhouses considering ecology }(2,4,12) \\
\text { Land allocation mode }(2,12) \\
\text { Design and manage FSDS infrastructure }(2,12) \\
\text { Maintain waste infrastructure disposal }(4,12) \\
\text { Training to traders and shopkeepers }(3,12) \\
\text { Levy taxes and markets fees }(6,12) \\
\text { Provide transport for FSDS }(2,12) \\
\text { Regulations } \\
\text { Land occupancy use }(2,7) \\
\text { Control production, processing and marketing } \\
\text { deeds }(3,7) \\
\text { Food quality standards }(5,7), \text { Meat inspection }(5,7) \\
\text { Hygiene and health in food processing }(5,7) \\
\text { Traffic management }(2,7) \text {, Pollution control }(4,7) \\
\text { Enforce legislation on water }(4,7)\end{array}$ & $\begin{array}{l}\text { Seek legal reforms for public } \\
\text { agencies roles clarifications } \\
\text { Identification of institutional and } \\
\text { departmental responsibilities } \\
\text { concerning FSDS (11) } \\
\text { Ensuring through training } \\
\text { motivation and monitoring that } \\
\text { personnel is equipped to meet the } \\
\text { growing food demand for } \\
\text { efficiency and accountability. } \\
(8,11)^{* * *}\end{array}$ & $\begin{array}{l}\text { Ensuring that the producers, } \\
\text { processors, transporters, } \\
\text { shopkeepers, consumers and } \\
\text { traders are voiced within the } \\
\text { central government (9) } \\
\text { Complementing efforts made } \\
\text { by farmers associations, } \\
\text { NGO's and local authorities in } \\
\text { rural and peri-urban areas to } \\
\text { lobby the central government } \\
\text { in order to reduce productions } \\
\text { constrains and strengthen } \\
\text { rural-urban linkages (10) }\end{array}$ \\
\hline
\end{tabular}

* Agents: producers, processors, traders, shopkeepers, street vendors, transporters and consumers. ${ }^{* *}$ Food Supply and Distribution Systems (FSDS). Policies topics within those 40 policies included (the number in the table refer to specific topic indicated with the same number within parenthesis): households (1); land use (2); supply and processing (3); environmental issues (4); health and nutrition issues (5); budget or capital levying from FSDS activities (6); other activities and actions included participation-dialogue with stakeholders for public policy ( 4 out of 40), interventions in the food market ( 3 out of 40 policies), information and education activities (4 out of 40 ). In addition, a classification of the type of policies is shown as follows: (a) law enforcement policies: (7), (b) policies related to information and education issues (8), (c) participation and dialogue to build public policy (9), (d) stakeholders collaboration for improvements of FSDS (10), (e) public administration clarification roles (11), (f) understanding and planning of FSDS (12). ${ }^{* * *}$ Policies in line with FAO's competence. 
The report "A briefing guide for Mayors, City Executives and Urban Planners in Developing Countries and Countries in Transition" [24] from the Food into Cities collection highlights the lack of planning and awareness of overcoming food demand due the blurred lines of responsibility between government agencies and insufficient consultation with market users. It initially focuses on issues related to the availability infrastructure, land, water, soil and forest resources to keep the FSDS working. According to it, the main cause of the lack of effective policy development is the inadequate understanding on: (1) urban consumers' food habits and purchasing behavior as well as local FSDS; (2) relevance of municipal budgeting, tax policies, public service delivery, trade and market regulations, public-private partnership frameworks for urban services, land-use planning and regulation; (3) need to incorporate FSDS aspects into planning at the regional, metropolitan and urban levels.

According to the mentioned report, there are three goals policies should be directed to:

(1) Economic Goal: efficiency and capability of the system to provide low cost food to low income consumers and food production incentives through equitable marketing opportunities for farmers

(2) Social Goal: minimizing food insecurity in poor households to achieve: improved equity from lower food prices; reduced social disruption, because supplies and prices are more stable; increased employment and income opportunities in the food sector

(3) Health and Environmental Goal: eliminate food-related health problems and minimize the FSDS activities on the environment by fostering: better hygiene conditions in the food chain; environmentally friendly and sustainable food production systems; better located, maintained and managed food market and processing infrastructure; better market and slaughterhouse waste disposal and use; better attention to ecological conditions of the city during planning.

The following section contains the consideration after FAO's policies analysis and classification resulted from the application of ST and SD approaches and the attention to the key points elicited from the FSDS framework model construction.

\section{Results and Limits of the FAO's Policy Analysis and System Thinking Solutions}

A clear definition of the main problem to be addressed with urgency is absent in the FAO policy design. Thus, proposed policies are generic and belonging to a different nature of issues, intervention scales and stakeholders' responsibility that might (or not) be related with the targeted area. Additionally, no method is suggested to assess policies and prioritize among them In FFFA we also observed a description of events that are part of the FSDS dynamics but a strict causality and categorization of dynamics is absent. It is assumed that external factors are stable in the short run or their change can be anticipated. According to FFFA system boundaries and changes are affected by: "External factors" which are the regulatory framework (laws) of the market interaction rules and stocks of infrastructure and land (urbanization, food needs, institutional constraints and services) and "Internal factors": these are food production and consumption items and their variables or drivers (consumer habits, supply chains, market strategies, distribution infrastructures). This type of categorization is not compatible for a system analysis; instead, a system analysis calls for the recognition of the endogenous variables which are part of the system structure and relevant for explaining the system behavior, exogenous variables, which are not specifically parts of the system structure. For instance, land and food needs (depending on population) considered external in FFFA are fundamental dynamic elements to explain the status and behavior over time of the food systems.

In reference to the report "A briefing guide for Mayors, City Executives and Urban Planners in Developing Countries and Countries in Transition" [24] none of the economic, social and health and environmental goals are related to the main one "Meeting urban food needs". Particularly, none of these goals was directly related to the increasing urbanization, which highlights the risk of not selecting significant policies to meet food needs and leaves the problem unaddressed.

FAO's policies recommendations correspond to structural and operational issues, being superior in number the operational proposals. The city majors are mentioned as the most relevant stakeholders 
but they lack capacity to implement structural solutions. Some of the required interventions suggested involve a stakeholders' variety, each with specific interests, where an agreement is unlikely to happen. Selecting accurate intervention is fundamental. An evaluation of the degree in which localities, scale highlighted by FAO, can address the main challenges their current metabolic flows present can be useful to identify other relevant stakeholders and other scales of intervention needed.

FAO as international organization has no coercive competence for intervention in the countries of study. Nevertheless, it explicitly offers to urban planners and local technical assistance for a proper understanding on the FSDS and the application of an interdisciplinary, multi-sectorial and participatory approach to find sustainable solutions [22]. As international organization, FAO, lacks of coercive capacity but has a potential role in disseminating useful information for better decision-making. It is important to take into account that FAO's goal might differ from the goals of food production and distribution agents.

FAO's FSDS assessment and policies suggested present opportunities on rethinking the level of intervention required to meet urban food needs and the stakeholders who should be involved. Often, the analysis of problems faced by society is limited to the operational issues of the single system to which decision makers' mental models relate the problem. However, designing a comprehensive policy for FSDS is not simple. The lack of alignment of goals with the system structural boundaries that generate the gaps will undermine the system performance improvement and make it dependent to symptomatic solutions.

An advice for FAO from system thinking is to look beyond the players, the rules; given that solving specific needs of agents, as numerous policies proposed, might not be as significant as analyzing interconnections among the system elements and identify the information and material flows that makes them operate in certain way [43]. Specifically, it could promote the FSDS dynamics understanding with its internal and external constrains for improving organization capacities and, finally, positively impact food security. Part of this useful information for decision makers should address the structural challenges for achieving food security especially of low income households and a critical perspective on consumption patterns and the balances with the production capacity of local food systems.

In addition, environmental goals are closely connected to urban food gaps because are functions of the territorial carrying capacity and should be taken into account as primary limiting factor. One core point to bring to the agenda is the urban growth trends which progressively downgrades the territories capacity for producing and distributing food. Cities viability and social resilience has to be assessed taking into account the current socio-economic structures and natural constrains of complete regions. Regional systems might still have the potential of supporting cities development and goals (including filling the food gaps) as long as they are coherent with their biophysical limits. Regions conform part of the macro-structure where production and consumption balances and territorial equities can be tested based on agro-ecological functions fulfillment of rural and urban spaces. Local strategies should be aligned to regional strategies, which assess in a systemic way the planetary boundaries under which all food supply and distribution activities depend on. There might be the need of scaling-up new institutional frameworks.

The main limitation of this work is its qualitative approach and the lack of consideration of the global scale in the proposed framework. Global and planetary issues often have local and specific consequences and should be considered in specific urban food policy assessments. Quantitative modeling of food systems within cities-region boundaries might be developed following the modeling steps of the SD techniques [42]. Similar model approaches have been successfully applied to increase food resilience in developing countries [44]. Starting from this work, the available causal map should be considered to identify the main stocks and should be modified to be applied to a specific case study. Historical trends of the identified gaps should be considered as reference mode for the model structure definition. Connections among variables should be validated with local experts. Parameterization and calibration should be performed considering historical trends of social 
and technical statistics available at local level. The final model will probably include a large amount of variables and the whole development should be performed by steps, finalizing the creation and validation of specific sub models. It will allow increasing both the level of details and robustness and affordability of the model outputs. Policy formulation and scenario analysis will take the last step. The modelling formulation and use should be guided by a multidisciplinary approach, as epistemic ground as a prior issue.

\section{Conclusions}

The food supply and distribution system (FSDS) model presented in this paper constitutes a framework which provides, in a simplified way, the dynamic structure between land, population, food distribution and production processes, resources, technology, economy and employment. The structural analysis of FSDS highlights the following as key elements towards a sustainable agri-food system in urban and rural territories: (1) FSDS mechanics are embedded in the field of Urban Dynamics: population, infrastructures growth and urbanization highly impact the FSDS organizational capability to provide food; (2) Conceiving population growth as the main problem in effectively feeding cities (thus given the raise in food demand) is only partially correct. The way most cities are conceived and structured is what contributes to the system being unsuccessful on meeting urban food needs; (3) Supply and Distribution Systems are just a part of a wider system. Urban, rural and peri-urban dynamics cannot be longer treated in isolation if the aim is to meet population food needs for the next decades. Cities metabolic processes are embedded in a growing urbanization trends where the processes to supply food are limited by the urban and rural structures of complete regions. Rural and Urban structures share important natural funds and their interaction is relevant on each other development. Concentrated and extended urbanization increase the pressures of FSDS systems. Innovations in agri-food systems and networks should not focus just on the operational issues of FSDS. Instead, the systemic perspective of this research has suggested take care of the structural issues of FSDS.

In the light of the limits of science while dealing with intervention in complex systems and the lack of information of agents within the system for optimal solutions, clarity on the information about the system's characteristics and conditions is useful to build on the current existing knowledge for modeling and simulation purposes. Complex system literature and Urban System frameworks offer new perspective for stakeholder orientating. Complex system methodologies can be used to assist autonomous stakeholders on their decisions. Simulation methods could be used as policy support tools to test the system response to operational and structural policies and find equilibrium states. Resilience and sustainability assessments are an example of the possible applications. Additionally, the study of production and consumption balances and urban metabolic processes are relevant research areas to test new paths towards the reconfiguration of food systems of cities and regions. Specifically, using urban metabolic goals and viability checks should support the assessment of production and consumption balances in specific urban context and from those, policy goals should be defined.

Acknowledging systems and regions as self-organizing systems opens the possibility for creating new institutional agreements and rules to embed an order principle on the design of new structures and assist agents' behavior. This could be a guide for rethinking human settlements and building other agri-food networks systems as it brings a different perspective on governance issues. Basically, the city change is constantly happening stimulated by some drivers responding to the system structure (decision rules and material elements). Understanding the feedback processes of a self-organized system instead of holding a linear-minded control aim reduces the attractiveness for top-down governance approaches. Deterministic and stochastic tools can help to grasp the complexity FSDS and cities and regions structures in order to inform policy makers about the system they are dealing with and improve the interventions. A new institutional framework for city-region governance should account for regional, continental and planetary issues. The cities development paradigm should be revisited considering the city-region systems constrains or ecological limits and socio-technical 
infrastructures should be adapted to those, and not the other way around, in order to make face to the current and future pressures on FSDS.

Acknowledgments: The authors would like to thank the Food and Agriculture Organization of the United Nations (FAO/AGS-Rome, Italy) for providing valuable information and prior knowledge of the FAO's FSDS Framework of Analysis, and for the precious information support while building FSDS framework.

Author Contributions: Vanessa Armendáriz designed the study, performed the research work, built the models and wrote most of the manuscript. Alberto Atzori contributed to writing, reviewing and editing of the manuscript. Stefano Armenia performed the revisions and provided advisory to this study.

Conflicts of Interest: The authors declare no conflict of interest.

\section{References}

1. Shaw, D.J. World Food Summit, 1996; World Food Security; Palgrave Macmillan: Basingstoke, UK, 2007; pp. 347-360.

2. Food and Agriculture Organization of the United Nations (FAO). Food into Cities. North-South Partnerships and Technical Cooperation between City and Local Authorities; Food into Cities Collection: Rome, Italy, 1999.

3. Sterman, J.D. System dynamics modeling: Tools for learning in a complex world. Calif. Manag. Rev. 2001, 43, 8-25. [CrossRef]

4. Senge, P.M. The Fifth Discipline: The Art and Practice of the Learning Organization; Doubleday Currency: New York, NY, USA, 1990.

5. Forrester, J.W. Counterintuitive behavior of social systems. Theory Decis. 1971, 2, 109-140. [CrossRef]

6. Morecroft, J.D. A critical review of diagramming tools for conceptualizing feedback system models. Dynamica 1982, 8, 20-29.

7. Forrester, J.W. Urban Dynamics; MIT Press: Cambridge, MA, USA, 1969.

8. Ramaswami, A.; Weible, C.; Main, D.; Heikkila, T.; Siddiki, S.; Duvall, A.; Pattison, A.; Bernard, M. A Social-Ecological-Infrastructural Systems Framework for Interdisciplinary Study of Sustainable City Systems. J. Ind. Ecol. 2012, 16, 801-813. [CrossRef]

9. Allen, P.M. Cities and Regions as Self-Organizing Systems: Models of Complexity; Routledge: London, UK, 2012.

10. Allen, P.M. Cities and regions as evolutionary, complex systems. Geogr. Syst. 1997, 4, 103-130.

11. Allen, P.M.; Sanglier, M. Dynamic models of urban growth. J. Soc. Biol. Struct. 1978, 1, 265-280. [CrossRef]

12. Batty, M. Cities as Complex Systems: Scaling, Interactions, Networks, Dynamics and Urban Morphologies; Working Papers Series No. 131, Center for Advanced Spatial Analysis, University College London. 2008. Available online: http:/ / discovery.ucl.ac.uk/15183/1/15183.pdf (accessed on 25 September 2015).

13. Pumain, D.; Swerts, E.; Cottineau, C.; Vacchiani-Marcuzzo, C.; Ignazzi, A.; Bretagnolle, A.; Delisle, F.; Cura, R.; Lizzi, L.; Baffi, S. Multilevel comparison of large urban systems. Phys. Soc. 2015. [CrossRef]

14. Garrison, W.L.; Berry, B.J.; Marble, D.F.; Nystuen, J.D.; Morrill, R.L. Studies of Highway Development and Geographic Change; University of Washington Press: Seattle, WA, USA, 1959.

15. Folke, C.; Carpenter, S.; Elmqvist, T.; Gunderson, L.; Holling, C.S.; Walker, B. Resilience and sustainable development: Building adaptive capacity in a world of transformations. Ambio 2002, 31, 437-440. [CrossRef] [PubMed]

16. Giampietro, M.; Aspinall, R.; Ramos-Martin, J.; Bukkens, S. Resource Accounting for Sustainability: The Nexus between Energy, Food, Water and Land Use; Routledge: London, UK, 2014.

17. Giampietro, M.; Mayumi, K.; Ramos-Martin, J. Multi-scale integrated analysis of societal and ecosystem metabolism (MuSIASEM): Theoretical concepts and basic rationale. Energy 2009, 34, 313-322. [CrossRef]

18. Forrester, J.W. Lessons from system dynamics modeling. Syst. Dyn. Rev. 1987, 3, 136-149. [CrossRef]

19. Argenti, O. Urban Food Security and Food Marketing; A Challenge to Cities and Local Authorities; Food into Cities Collection: Rome, Italy, 1999.

20. Argenti, O. Food into Cities: Selected Papers; FAO Agricultural Services Bulletin No. 132; Food and Agriculture, Organization of the United Nations (FAO): Rome, Italy, 1999.

21. Food and Agriculture Organization of the United Nations (FAO). Feeding the Cities. In: The State of Food and Agriculture 1998; Food into Cities Collection: Rome, Italy, 1998.

22. Aragrande, M.; Argenti, O. Studying Food Supply and Distribution Systems to Cities in Developing Countries and Countries in Transition: Methodological and Operational Guide; Food into Cities Collection: Rome, Italy, 2001. 
23. Food and Agriculture Organization of the United Nations (FAO). A Policy Framework for Municipal Authorities on Growing Cities; Growing Food: Rome, Italy, 2000.

24. Argenti, O. Food for the Cities: Food Supply and Distribution Policies to Reduce Urban Food Insecurity; Food and Agriculture Organization of the United Nations (FAO): Rome, Italy, 2001.

25. Armendariz, V.; Atzori, A.; Armenia, S.; Romano, A. Analyzing Food Supply and Distribution Systems using complex systems methodologies. In Proceedings of the 9th Igls-Forum on System Dynamics and Innovation in Food Networks, Innsbruck, Austria, 9-13 February 2015.

26. Armendariz, V.; Atzori, A.; Armenia, A. Understanding the Dynamics of Food Supply and Distribution Systems (FSDS); Food and Agriculture Organization of the United Nations: Rome, Italy, 2015.

27. Sterman, J.D. Business Dynamics: Systems Thinking and Modeling for a Complex World; McGraw-Hill: New York, NY, USA, 2000.

28. Ford, A. Modeling the Environment: An Introduction to System Dynamics Models of Environmental Systems; Island Press: Washington, DC, USA, 2009.

29. Ostrom, E. Understanding Institutional Diversity; Princeton University Press: Princeton, NJ, USA, 2005.

30. Ravetz, J. Integrated assessment for sustainability appraisal in cities and regions. Environ. Impact Assess. Rev. 2000, 20, 31-64. [CrossRef]

31. Rosser, J.B. Complex Evolutionary Dynamics in Urban-Regional and Ecologic-Economic Systems: From Catastrophe to Chaos and Beyond; Springer Science \& Business Media: New York, NY, USA, 2011.

32. Walker, B.; Carpenter, S.; Anderies, J.; Abel, N.; Cumming, G.; Janssen, M.; Lebel, L.; Norberg, J.; Peterson, G.D.; Pritchard, R. Resilience management in social-ecological systems: A working hypothesis for a participatory approach. Conserv. Ecol. 2002, 6, 14. [CrossRef]

33. Armenia, S.; Misuraca, G.C.; Osimo, D.; Mureddu, F. A New Roadmap for Next-Generation Policy-Making. In Proceedings of the 6th International Conference on Theory and Practice of Electronic Governance (ICEGOV2012), Albany, NY, USA, 22-25 October 2012.

34. Meadows, D.H.; Meadows, D.L.; Randers, J. Beyond the Limits: Confronting Global Collapse, Envisioning a Sustainable Future; Chelsea Green: Post Mills, VT, USA, 1992.

35. Brenner, N. Urban Governance-At What Scale? LSE Cities: London, UK, 2014.

36. Bertuglia, C.S.; Vaio, F. Cities as Factors and Places of development: Non-linear interactions, self-organization and emerging trends. Rev. Econ. Cond. Italy 2011, 2, 381-467.

37. Bertuglia, C.S.; Vaio, F. The Complexity Approach to the Study of Urban Systems; The City Crisis: The Priority of the XXI Century; Fondazione Aldo Della Rocca: Roma, Italy, 2011; pp. 500-515.

38. Bertuglia, C.S.; Bianchi, G.; Mela, A. The City and Its Sciences; Springer Science \& Business Media: New York, NY, USA, 2012.

39. Golubiewski, N. Is There a Metabolism of an Urban Ecosystem? An Ecological Critique. Ambio 2012, 41, 751-764. [CrossRef] [PubMed]

40. Walloth, C.; Gurr, J.M.; Schmidt, A.J. Understanding Complex Urban Systems; Springer: New York, NY, USA, 2014.

41. Giampietro, M.; Mayumi, K.; Sorman, A.H. Energy Analysis for a Sustainable Future: Multi-Scale Integrated Analysis of Societal and Ecosystem Metabolism; Routledge: London, UK, 2013.

42. Armendariz, V.; Armenia, S.; Atzori, A. SD Updates of FAO Methodological Guide to manage the Food Supply and Distribution Systems (FSDS). In Proceedings of the 33rd International System Dynamics Conference (ISDC), Cambridge, MA, USA, 19-23 July 2015.

43. Meadows, D.H. Thinking in Systems: A Primer; Chelsea Green Publishing: Post Mills, VT, USA, 2008.

44. Herrera, H.; Kopainsky, B. Rethinking agriculture in a shrinking world: Operationalization of resilience with a System Dynamics perspective. In Proceedings of the 33rd International System Dynamics Conference (ISDC) 2015, Cambridge, MA, USA, 19-23 July 2015.

(C) 2016 by the authors; licensee MDPI, Basel, Switzerland. This article is an open access article distributed under the terms and conditions of the Creative Commons Attribution (CC-BY) license (http://creativecommons.org/licenses/by/4.0/). 